\title{
Omento-myelo-synangiosis in the Management of Chronic Traumatic Paraplegia: Case Report
}

\author{
Jacob Abraham, M.B., M.S., M.S., F.A.C.S., F.A.C.A., F.A.M.S., ${ }^{1}$ Alister \\ Paterson, F.R.C.S., ${ }^{1}$ Mohan Bothra, M.S. F.R.C.S., ${ }^{1}$ Adnan B. Mofti, \\ F.R.C.S. (Eng.) F.R.C.S. (Glas.)., ${ }^{2}$ and Gerard W. Taylor, F.R.C.S. \\ (Eng.) ${ }^{2}$ \\ ${ }^{1}$ Division of Neurosurgery, Department of Surgery, ${ }^{2}$ Division of General Surgery, \\ Department of Surgery King Khalid University Hospital
}

\begin{abstract}
Summary
A case of traumatic paraplegia, with almost complete motor and sensory loss up to the umbilicus, who had an operation for post traumatic arachnoiditis and diagnosed as having recurrence of arachnoiditis and traumatic syringomyelia and treated by a pedicled omental onlay graft to the spinal cord, is described. The patient made a remarkable recovery and 1 year after surgery he continues to maintain excellent progress. He is now able to walk with support and is completely independent. It is suggested that chronic paraplegics should be assessed for possible arachnoiditis and traumatic syringomyelia and if detected an omental transposition be considered as one means of increasing rehabilitation potential.
\end{abstract}

Key words: Chronic traumatic paraplegia; Arachnoiditis; Traumatic syringomyelia; Pedicled omental transposition.

\section{Introduction}

The term omento-myelo-synangiosis describes an operation which utilises a pedicled omental on-lay graft on to the spinal cord; vascular connections between the two with consequent augmented local spinal cord blood flow, is implied. The rationale for such a procedure is based on the understanding that a significant sequelae of spinal cord trauma is chronic local ischaemia (Bingham, 1975; Crawford, 1977; Ducker, 1976; 1971; 1978; Griffiths, 1976; Kobrine, 1975; Sandler, 1976; Smith, 1978) and that the omentum possesses an extraordinary capacity for revascularisation (Thompson, 1945; Myllasniemi, 1968; Eliska 1968). The pathology, neuroradiology and experimental data supporting the rationale of the present management is reviewed in detail below.

This report describes a case of chronic traumatic paraplegia treated by omental transposition followed with a remarkable recovery which he has maintained on follow up for the past 1 year. 
This is the first case of this type reported in the Middle East and probably in world literature.

\section{Patients and methods}

A 25-year-old Saudi fell off the roof of his house in 1981 . He was immediately admitted into one of the hospitals in Riyadh and an emergency laparotomy performed for a ruptured diaphragm. When he regained consciousness approximately 48 hours after admission, he noticed he could not move both lower limbs and had no sensation up to the level of his umbilicus. He did not have control of bladder or bowel. He was informed that he had a fracture of his spine and spinal cord damage. He gradually began to recover motor power and sphincter control and in a year's time he was able to walk unaided. He also regained sphincter control. However, girdle pains and persisiting right leg weakness made him seek further help in another country, where after a myelogram post-traumatic arachnoiditis was diagnosed and laminectomy and release of arachnoidal adhesions carried out in 1982 . He was relieved of pain and started walking again. Six months later he noticed gradually increasing weakness of both legs with tremor and spasticity and shortly thereafter he was unable to walk. Since 1983 he had been restricted to a wheelchair. He was admitted to this hospital on April 24, 1985.

He was a lean healthy looking young man confined to a wheelchair. He had almost total motor and sensory loss below the level of the umbilicus, with marked wasting of the thigh and calf muscles associated with bilateral severe spasticity and contractures of the adductors of the hips, hamstrings and both tendo-achilles. He had a small bedsore over the coccygeal area. He was continent. There was a healed midline scar over the mid-dorsal region. The muscle power on admission and before surgery is shown in Table 1.

Table I Pre-operative Muscle Assessment 1/5/85

\begin{tabular}{lll}
\hline & $\mathbf{R}$ & $\mathbf{L}$ \\
\hline Toes & & \\
Flex & 0 & 1 \\
Ext & 0 & 0 \\
Ankle & & \\
Flex & 0 & 0 \\
Ext & 0 & 0 \\
Inv & 0 & 0 \\
Ev & 0 & 0 \\
Knee & & \\
Flex & 0 & 1 \\
Ext & 0 & 1 \\
Hip & & \\
Abd & 2 & 2 \\
Add & 2 & 2 \\
Flex & 1 & 1 \\
Ext & 1 & 1 \\
Med. Root & 1 & 1 \\
Lat. Rot. & 1 & 1 \\
\hline
\end{tabular}

Muscle scored: From 0 to 5 


\section{$X$-ray Spine}

Anterior-posterior and lateral views of the dorsal spine showed evidence of laminectomy from $D_{6}-D_{10}$ and minimal changes in the body of $D_{9}$ and $D_{10}$ vertebrae consistent with healed fracture.

\section{Myelogram}

With metrizamide and myodil via the lumbar and cervical route, showed evidence of hold up of the contrast at $\mathrm{D}_{5} / \mathrm{D}_{6}$ and $\mathrm{D}_{12} / \mathrm{D}_{11}$; with some droplets of dye in between, consistent with extensive arachnoiditis. (See Fig. 1a and 1b)

\section{C.T. Scan}

Showed a homogeneous density of contrast around the cord up to $\mathrm{D}_{10}$. At $\mathrm{D}_{9}$ instead of a cord shadow the contrast was seen filling the area of the cordprobable cyst formation. (See Fig. 2a and 2b)

Under general anaesthesia, the patient was positioned on his left side with the back $90^{\circ}$ to the floor and the pelvis taped to the table. Two teams of surgeons, one for the abdominal end and the other for the spine were used. The spinal incision started at the midline opposite $\mathrm{D}_{4}$, curved paramedian to the right and ended in the midline opposite $\mathrm{D}_{10} / \mathrm{D}_{11}$. The skin and subcutaneous tissue were
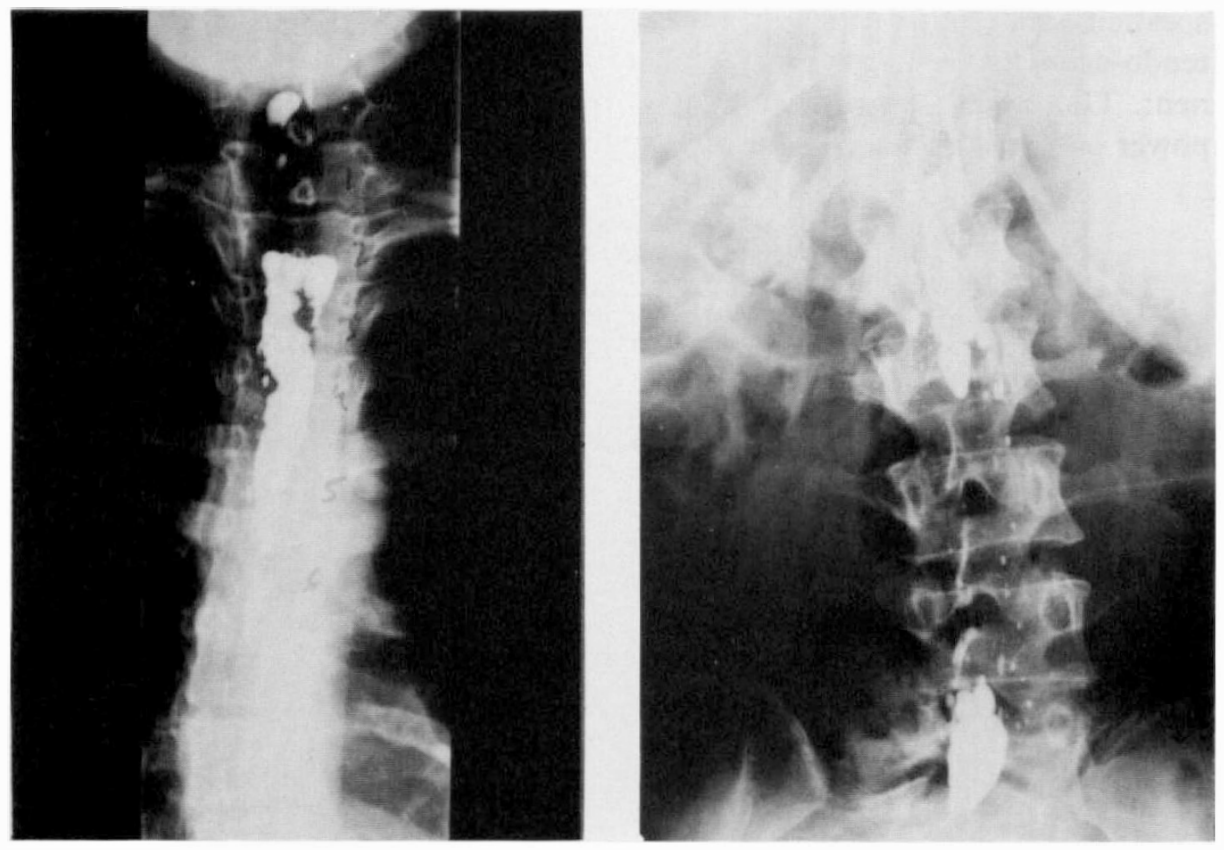

Figure 1a Shows hold up of the dye opposite $\mathrm{D}_{5} / \mathrm{D}_{6}$. Upper limit of arachnoiditis.

Figure 1b Shows hold up of the dye opposite $D_{11} / D_{12}$, when injected from below. Lower limit of arachnoiditis. 

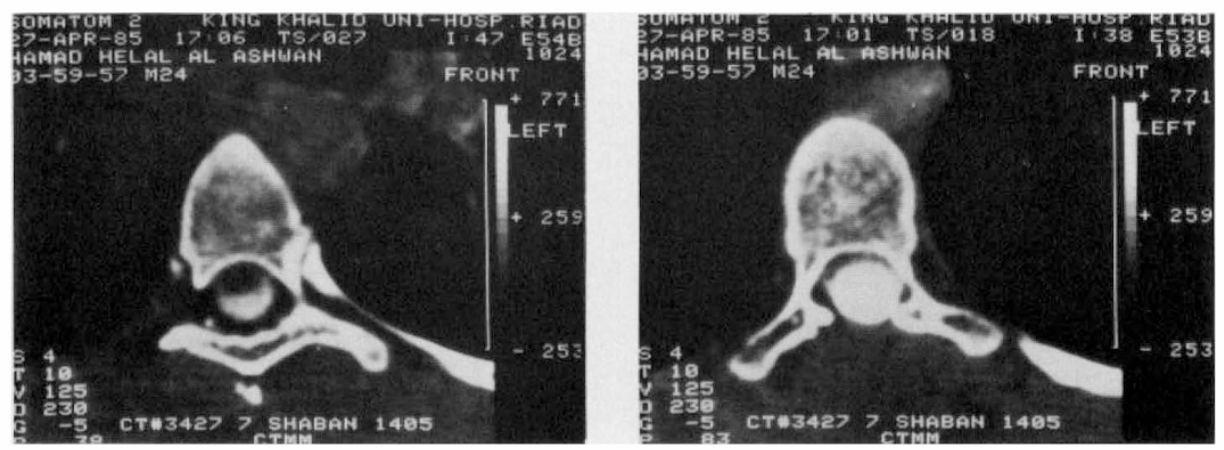

Figure 2a C.T. scan with intrathecal Metrizamide showing some dye over the dorsal aspect of the spinal cord.

Figure 2b C. T. scan showing a dye-filed cyst at $\mathrm{D}_{9}$ with no discernible spinal cord.

reflected off as a flap and hinged a little to the left of the midline, the paraspinal muscles were cut along the midline and held apart by means of a self-retaining retractor. The laminae of $\mathrm{D}_{5} / \mathrm{D}_{6}$ and $\mathrm{D}_{10}$ was exposed. The dura was then carefully excised along the whole exposed length. Dense arachnoidal adhesions were found throughout the length of the exposed cord. Three arachnoidal cysts and one large syrinx were also seen. The syringomyelic cavity was situated at the lower end of the exposed spinal cord and was opened by incising the thin layer of spinal cord over approximately $75 \%$ of its length. The cord tissue around the cyst appeared paper thin. The operating microscope was used throughout the dissection.

In the meantime the abdominal team had entered the abdomen through a right subcostal incision, detached the greater omentum from the transverse colon, splenic area and from the left side of the greater curvature after ligating the left gastro-epiploic artery. An incision was then made between the arterial arcades of the omentum so as to effectively lengthen it at the same time preserving its blood supply via its attachment on the right side. It was then brought out of the abdominal cavity and tunneled subcutaneously to the incision on the back. The tunnelling was facilitated by a small incision between the right costal and spinal incisions. The abdominal wound was closed leaving the upper end of the incision wide enough to allow egress of the omentum without compression. The omentum was laid onto the exposed spinal cord and held in place with stitches to the cut end of the dura. Both wounds were closed without a drain. The patient withstood the operation well and was brought back to the ward in a good condition.

The post-operative course was uneventful and within 2 weeks of surgery minor improvement in motor and sensory functions were evident. The spasticity was also markedly reduced. The subsequent improvement in motor function is tabulated (See Table II).

\section{Discussion}

The result achieved assessed 1 year after surgery has been excellent. The precise role played by the transposed pedicled omentum is as yet unclear, though it 
Table II Post-operative Muscle Assessments

\begin{tabular}{|c|c|c|c|c|c|c|c|c|}
\hline & \multicolumn{2}{|c|}{$25 / 7 / 1985$} & \multicolumn{2}{|c|}{$5 / 8 / 1985$} & \multicolumn{2}{|c|}{$1 / 10 / 1985$} & \multicolumn{2}{|c|}{$31 / 3 / 1986$} \\
\hline & $\mathrm{R}$ & $\mathrm{L}$ & $\mathrm{R}$ & $\mathrm{L}$ & $\mathrm{R}$ & $\mathrm{L}$ & $\mathrm{R}$ & $\mathrm{L}$ \\
\hline \multicolumn{9}{|l|}{$\overline{\text { Toes }}$} \\
\hline Flex & 1 & 1 & 3 & 2 & 3 & 2 & 4 & 2 \\
\hline Ext & 1 & 1 & 3 & 1 & 3 & 1 & 4 & 2 \\
\hline \multicolumn{9}{|l|}{ Ankle } \\
\hline Flex & 0 & 1 & 3 & 1 & 3 & 1 & 4 & 1 \\
\hline Ext & 1 & 2 & 3 & 1 & 3 & 1 & 3 & 3 \\
\hline Inv & 1 & 1 & 4 & 2 & 4 & 1 & 4 & 2 \\
\hline $\mathrm{Ev}$ & 0 & 0 & 2 & 1 & 2 & 1 & 4 & 3 \\
\hline \multicolumn{9}{|l|}{ Knee } \\
\hline Flex & 1 & 2 & 2 & 2 & 3 & 3 & 4 & 3 \\
\hline Ext & 2 & 2 & 4 & 3 & 4 & 3 & 4 & 3 \\
\hline \multicolumn{9}{|l|}{ Hip } \\
\hline Abd & 1 & 2 & 3 & 3 & 3 & 3 & 4 & 3 \\
\hline Add & 2 & 2 & 4 & 3 & 4 & 3 & 4 & 3 \\
\hline Flex & 2 & 2 & 4 & 4 & 4 & 4 & 4 & 4 \\
\hline Ext & 2 & 2 & 3 & 2 & 3 & 2 & 3 & 2 \\
\hline Med. Rot & 2 & 2 & 3 & 3 & 3 & 3 & 4 & 3 \\
\hline Lat. Rot & 1 & 2 & 3 & 2 & 3 & 2 & 4 & 2 \\
\hline
\end{tabular}

Muscle scored: From 0 to 5

may be conjected that the recurrence of arachnoidal adhesions and the accumulation of C.S.F. in the arachnoid and syringomyelic cysts have been prevented. It may be noted that after a previous attempt at surgery for removal of arachnoidal adhesions, he had become completely paraplegic within 6 months, after initial improvement. Neuroradiologic studies in chronic traumatic paraplegia have not been very frequent due perhaps to an erroneous understanding by those concerned that a 'plateauing off' in improvement indicated maximal achievement of potential.

In a very important contribution to the subject (Perovitch, 1983) examined 125 patients in the chronic phase of spinal cord injury and was able to compare neuroradiological findings with subsequent pathological or surgical exploration. He classified post-traumatic changes into:

1. An intramedullary syrinx.

2. Atrophy of the spinal cord.

3. Adhesions.

4. Vascular alterations and

5. The effects of a post traumatic encapsulated extra-medullary cyst and also observed that some of these changes were often combined. He also concluded that impairment of flow occurred in an injured cord which could lead to progressive atrophy of its substance.

At surgery the following abnormalities were noticed in this case; arachnoiditis, arachnoidal cysts, traumatic syringomyelic cavities and a paper-thin spinal cord surrounding the largest syrinx with very few detectable arteries and veins on the dorsal surface of the cord. Following release of arachnoidal adhesions the blood vessels, the veins in particular, became more visible and distended.

The ability of the pedicled omentum to revascularise normal and traumatised spinal cord has been reported by Goldsmith, et al. $(1975 ; 1983)$. He clearly demonstrated vascular connections between the omentum and the pia-arachnoid 
and via these connections into the intrinsic blood vessels of the cord in dogs and cats. One of the authors (J.A.) has been able to confirm that pedicled omental transposition onto the damaged (contused) area of the primate spinal cord achieves absorption of oedema and provides an added means of local vascular supply Theodore, et al. (1984). The same author has had equally encouraging results following omental transposition to the spinal cord in cases of healed tuberculous arachnoiditis ( 4 cases) and syringomyelia ( 2 cases).

It appears from these observations that chronic paraplegic patients who cease to improve as a result of arachnoiditis or cyst formation, may achieve further improvement, if appropriate management is offered.

\section{References}

Bingham WG, Goldman H, Friedman SJ, et al. 1975 Blood flow in normal and injured monkey spinal cord. Journal of Neurosurgery 43:162-171.

CRAWFORD RA, GRIFFITHS IR, MCCulloch J 1977 The effect of norepinephrine on the spinal cord circulation and its possible implications in the pathogenesis of acute spinal trauma. Journal of Neurosurgery 47:567-576

DUCKER TB 1976 Experimental injury of the spinal cord. In: Handbook of clinical neurology. Vinken P, Bruyn GW (eds), Vol. 25 p. 9-26.

DuCKer TB, PEROT PL 1971. Spinal cord oxygen and blood flow in trauma. surg. Forum 22:413415.

Ducker TB, Solomon M, LuCAS JT, et al. 1978 Blood flow, tissue oxygen, evoked potentials in both paretic and plegic monkeys. Surgical Neurology 10:64-70.

ElisKA O 1968 Blood flow in the revascularized kidney. Journal of Cardiovascular Surgery (Torino) 9:342-347.

GoldSMITh HS, DUCKETT S, CHEN WF 1975 Spinal cord vascularization by intact omentum. American Journal of Surgery 129:262-265.

Goldsmith HS, STEWARD E, CHEN WF, et al. 1983 Application of intact omentum to the normal and traumatised spinal cord. In Kao CC, Bunge RP, Reir RJ, (eds). Spinal cord reconstruction. Raven Press, New York.

GoldSMith HS, STEWARD E, DUCKETt S 1985 Early application of pedicled omentum to the acutely traumatised spinal cord. Paraplegia, 23:100-112.

GRIFFITHS IR 1976 Spinal cord blood flow after acute experimental cord injury in dogs. Journal of Neurology Sci 27:247-259.

Kobrine, AI, Doyle TF, MARTins AN $1975^{2}$ Local spinal cord blood flow in experimental traumatic myelopathy. Journal of Neurosurgery 42:144-149.

MYLLARNIEMI H, KARPPINEN V 1968 Vascular pattern of peritoneal adhesions. British Journal of Surgery. 55:605-608.

PEROVITCH M 1983 Neuroradiology of the sequelae of spinal cord trauma. Acta Neurochirrugica. Supplementum 32:91-94.

SANDLER AN, TATOR CH 1976 Review of the effect of spinal cord trauma on the vessels and blood flow in the spinal cord. Journal of Neurosurgery 45:638-646.

Smith AJK, MCCreery DB, Bloedel JR, et al. 1978 Hyperemia, $\mathrm{C}_{0} 2$ responsiveness, and autoregulation in the white matter following experimental spinal cord injury. Journal of Neurosurgery $81,48-239-251$

TheODORE DR, ABraham J 1985 Indian Journal of Medical Research 81 Feb. pp. 209-214.

Thompson SA, Pollock B 1945 The use of the omental grafts in the thorax. An experimental study. American Journal of Surgery 70:227-231.

Editorial Note The operative procedure described in this paper is at an early stage of evaluation. Whilst publication of this and similar reports is important, it does not imply a recommendation of this procedure, by this journal, as a standard treatment of traumatic spinal cord injury. 